\title{
Intraoperative radiotherapy with low energy $x$-rays for primary and recurrent soft-tissue sarcomas
}

\author{
Gustavo R. Sarria', Vera Petrova', Frederik Wenz ${ }^{2}$, Yasser Abo-Madyan', Elena Sperk ${ }^{1 \dagger}$ and Frank A. Giordano ${ }^{1,3^{*}+}$ (D)
}

\begin{abstract}
Background: Soft tissue sarcomas (STS) treatment remains a therapeutic challenge. Intraoperative radiotherapy (IORT) resembles a safe and efficient for STS treatment. The first data on electronic-IORT (elORT) using low-energy photons is herein presented.
\end{abstract}

Methods: Thirty-one patients with newly and recurrent STS were retrospectively assessed. EIORT was applied with low-energy photons during surgery. The dose was either prescribed to the applicator surface (spherical applicators) or $5 \mathrm{~mm}$ depth (flat applicators). Overall progression-free survival (O-PFS), local progression-free survival (L-PFS), overall survival (OS) and adverse events were evaluated.

Results: Median follow-up was 4.88 (1.0-8.95) years. Twenty-five patients (80.6\%) had recurrent STS with prior treatment. The resection status was R1 in 25.8\% and R2 in 6.5\%. The distribution was 51.7\% for extremities, 35.5\% for abdomen and pelvis, 9.7\% for thorax and 3.2\% for head and neck tumors. The median O-PFS was 11.0 months, with 42.6\% 5-year estimated O-PFS. The only local recurrence in the primary setting occurred after 22 months. Median L-PFS in recurrent STS was 12.5 months, with 65.5\% 5-year estimated L-PFS. The 5-year OS estimated rate was $94.7 \%$ (3 events after 7 years). No G3 toxicity related to elORT was observed. Two patients exhibited G2 acute neuropathic pain. Late neuropathic pain was seen in 6 patients being 3 graded as G1 and 3 as G2. No woundrelated toxicity was found.

Conclusion: Electronic IORT with low-energy photons is a safe treatment option for STS, yielding similar outcomes as historical series reporting IORT with electrons or HDR brachytherapy.

Keywords: Soft-tissue sarcoma, Electronic intraoperative radiotherapy, IORT, Kilovoltage, Low energy x-rays

\footnotetext{
*Correspondence: frank.giordano@ukbonn.de; Frank.Giordano@umm.de

${ }^{\dagger}$ Elena Sperk and Frank A. Giordano share senior authorship.

'Department of Radiation Oncology, University Medical Center Mannheim, Medical Faculty Mannheim, Heidelberg University, Theodor-Kutzer-Ufer 1-3, 68167 Mannheim, Germany

${ }^{3}$ Department of Radiation Oncology, University Hospital Bonn, University of Bonn, Venusberg Campus 1, 53127 Bonn, Germany

Full list of author information is available at the end of the article
}

(c) The Author(s). 2020 Open Access This article is licensed under a Creative Commons Attribution 4.0 International License, which permits use, sharing, adaptation, distribution and reproduction in any medium or format, as long as you give appropriate credit to the original author(s) and the source, provide a link to the Creative Commons licence, and indicate if changes were made. The images or other third party material in this article are included in the article's Creative Commons licence, unless indicated otherwise in a credit line to the material. If material is not included in the article's Creative Commons licence and your intended use is not permitted by statutory regulation or exceeds the permitted use, you will need to obtain permission directly from the copyright holder. To view a copy of this licence, visit http://creativecommons.org/licenses/by/4.0/. The Creative Commons Public Domain Dedication waiver (http://creativecommons.org/publicdomain/zero/1.0/) applies to the data made available in this article, unless otherwise stated in a credit line to the data. 


\section{Introduction}

With an approximate overall incidence of 6/100000 [1] and less than $1 \%$ of the all-cancers global prevalence, sarcoma is a rare tumor entity [2]. However, it accounts for 13.040 new patients per year in the US [3] and the overall lethality of this tumor is still high [4].

Tumor recurrence usually occurs within the first 18 months of treatment and depends on many variables such as primary location, histology, stage or resection status [5-7]. The cornerstone for sarcoma management remains to be the upfront surgical approach and the addition of radiotherapy in cases where needed $[8,9]$, according to a variety of features listed in different international guidelines [10], which enhances the therapeutic ratio compared to a single-intervention approach, as randomized trials have previously reported with an overall local control rate increase of $20-25 \%$ [11, 12]. In consequence, treatment strategies may vary depending on these factors [13]. Historical data shows that approximately $50 \%$ of patients with primary retroperitoneal tumors do not achieve a complete resection due to anatomic challenges and even in case tumors were completely resected, patients still exhibit a 50\% risk for recurrence [13]. Thus, the nature of this tumor also represents a challenge for the radiation oncologist, as the best response outcomes after radiotherapy are seen after complete resection [14, 15]. Regarding extremity sarcomas, the greatest benefit of this treatment might be related to limb-sparing surgery, as the increased local control yields in lower recurrence rates, therefore fewer salvage amputations would be needed [16].

Amongst all therapeutic options, intraoperative radiotherapy (IORT) has been used for additional tumor bed treatment for more than 50 years as it results in improved outcomes in terms of local control [17, 18]. However, IORT was either applied using forward-directed electron beams or using high-dose rate (HDR) brachytherapy with flexible applicators ("flabs") that were placed on the tumor bed and then after-loaded with ${ }^{192}$ Ir or ${ }^{60} \mathrm{Co}$ sources $[19,20]$. A further, more recent intraoperative treatment option is the use of a portable linear accelerator delivering low-energy $(50 \mathrm{kV})$ photons [21]. This system is FDA-approved for treatment of all tumors within the human body has it proven safe and efficient in a variety of phase I-III trials [22-25]. We treated a total of 31 patients with primary and recurrent soft-tissue sarcoma with this novel modality and here for the first time report the results of a retrospective analysis of their outcome.

\section{Methods}

\section{Patient selection and procedures}

Patient charts of 31 patients with primary and recurrent soft-tissue sarcoma STS treated at our institution between December 2008 and June 2017 were retrospectively analyzed. All patients underwent surgery after MRI-based diagnosis establishment and preoperative feasibility assessment. During resection, patients were treated (Intrabeam, Carl Zeiss Meditec AG, Oberkochen, Germany) with either a forward-beaming flat applicator (providing dose uniformity ["flatness"] perpendicular to the beam direction greatest at the prescription depth of $5 \mathrm{~mm}$ ) or a ball-shaped applicator providing a spherical isotropic dose distribution [21, 26], for which the resection borders were approached with a purse-string-like suture. Depending on region, risk structures and previous EBRT irradiation, electronic IORT (eIORT) was delivered with doses between 5 and 20 Gy prescribed to $5 \mathrm{~mm}$ (flat applicator) or at the applicator surface (spherical applicators). Doses were chosen after these considerations and clinician's discretion. The applicator was selected in-situ according to the surgical bed morphology, assuring an adequate coverage of the intended area to treat. The region that was judged clinically to be the area with highest likelihood of residual tumor or R2 situation under direct observation was defined as target volume, as discussed between the surgeon and the radiation oncologist and based on the limitations for further resection.

This study was approved by local Ethics committee, according to institutional protocols. All patients gave informed consent prior to treatment application. All ethics standards were applied according to the Declaration of Helsinki.

\section{Outcome assessments}

Factors of interest were age, gender, location, histology, previous and subsequent therapies as well as response determined in regular follow-ups including imaging. Staging was performed through MRI and thorax-CT. All patients undergoing IORT were scheduled for 1st-, 3rd-, 6th -, 12th -, 18th,- 24th-month and afterwards yearly post-treatment follow-ups, with 6-month interval MRI and thorax-CT during the first 2 years and annual thereafter. Progression-free survival (PFS) and overall survival (OS) were defined as time from eIORT until tumor recurrence at any site or death by any cause. Local PFS (L-PFS) was defined as time from eIORT until local tumor recurrence or death event. The entire tumor bed was considered for L-PFS purposes. Toxicity was assessed according to the Common Terminology Criteria for Adverse Events (CTCAE, v. 5.0). The cutoff between acute and late toxicities was defined to be 3 months after eIORT. All statistical analyses were carried out using SPSS (Version 24.0., IBM, Armonk, NY), and significance was assess as per the $\mathrm{t}$-test.

\section{Results}

Patient collective

We analyzed charts of 15 female and 16 male patients (Table 1). The median follow-up was 4.88 years (range: $1.0-8.95$ years). The median age was 48 years $(15-77$ 
Table 1 Patient characteristics

\begin{tabular}{|c|c|c|}
\hline Characteristic & $\mathrm{N}$ & $\%$ \\
\hline \multicolumn{3}{|l|}{ Age } \\
\hline Median Age (Range) [years] & $48[15-77]$ & \\
\hline \multicolumn{3}{|l|}{ Gender } \\
\hline Male & 16 & 51.6 \\
\hline Female & 15 & 48.4 \\
\hline \multicolumn{3}{|l|}{ Disease Status } \\
\hline Primary & 6 & 19.4 \\
\hline Recurrent & 25 & 80.6 \\
\hline \multicolumn{3}{|l|}{ Tumor Location } \\
\hline Upper extremity & 3 & 9.7 \\
\hline Lower extremity & 13 & 42 \\
\hline Abdomen/pelvis & 11 & 35.5 \\
\hline Thorax & 3 & 9.7 \\
\hline Head and neck & 1 & 3.2 \\
\hline \multicolumn{3}{|l|}{ Histology } \\
\hline Liposarcoma & 9 & 29.0 \\
\hline Leiomyosarcoma & 3 & 9.7 \\
\hline Myxofibrosarcoma & 3 & 9.7 \\
\hline Neurofibrosarcoma & 4 & 12.9 \\
\hline Others & 12 & 38.7 \\
\hline \multicolumn{3}{|l|}{ Grading } \\
\hline G1 & 6 & 19.4 \\
\hline $\mathrm{G} 2$ & 8 & 25.8 \\
\hline G3 & 8 & 25.8 \\
\hline Unknown & 9 & 29.0 \\
\hline \multicolumn{3}{|l|}{ Tumor Size } \\
\hline Mean/Range $[\mathrm{cm}]$ & $7.1[1.8-22.0]$ & \\
\hline \multicolumn{3}{|l|}{ Prior RT } \\
\hline Yes & 13 & 41.9 \\
\hline No & 18 & 58.1 \\
\hline \multicolumn{3}{|l|}{ Resection Status } \\
\hline RO & 18 & 58.1 \\
\hline R1 & 8 & 25.8 \\
\hline R2 & 2 & 6.5 \\
\hline Unknown & 3 & 9.7 \\
\hline \multicolumn{3}{|l|}{ IORT } \\
\hline Spherical applicator & 28 & 90.3 \\
\hline Flat applicator & 3 & 9.7 \\
\hline Dose (Range) [Gy] & $5-20$ & \\
\hline \multicolumn{3}{|l|}{ EBRT after IORT } \\
\hline Yes & 15 & 48.4 \\
\hline No & 16 & 51.6 \\
\hline \multicolumn{3}{|l|}{ Systemic therapy after IORT } \\
\hline Yes & 9 & 29.0 \\
\hline No & 22 & 71.0 \\
\hline
\end{tabular}

years). The mean tumor size was $7.1 \mathrm{~cm}(1.8-22)$. Of all 31 patients, 16 had extremity sarcoma (51.7\%), 14 had a diagnosis of pelvic and abdominal tumors (35.5\%), 3 had thoracic sarcoma (9.7\%) and 1 patient had a head and neck primary sarcoma (3.2\%). Twenty-five patients $(80.6 \%)$ had recurrent disease and were previously treated (surgery and/ or external beam radiotherapy [EBRT]). Four patients with previously un-irradiated recurrences received neoadjuvant EBRT. The post-recurrence surgical margin status was found to be R0 in 18 patients (58.1\%), R1 in 8 patients (25.8\%), R2 in 2 patients (6.5\%), and not clear in 3 patients (9.7\%).

\section{Efficacy outcomes}

The median O-PFS was 11.0 months for both primary and recurrent tumors (range: 10-12 months for primary and 3-38 months for recurrent tumors). The 5-year estimated O-PFS was $42.6 \%$ Fig. 1a (62.5 and $38.1 \%$ for primary and recurrent $[p=0.316]$, respectively, Fig. 2a). Distant metastasis events were recorded in 7 recurrent STS patients and 1 primary STS patient after 10 months. Only one local recurrence occurred in the group of patients with primary STS after 22 months and 8 in the recurrent group. The median L-PFS in the group with recurrent STS was 12.5 months (3-38 months) and the estimated 5-year L-PFS was $65.5 \%$ (Fig. $1 \mathrm{~b}$ and Fig. 2b). The 5 -year OS estimated rate was $94.7 \%$ Fig. 1c (1 event for primary and 2 events for recurrent [ $p=0.725], \mathrm{c})$. There was no statistically significant difference amongst anatomical location in terms of O-PFS $(p=0.685)$, LPFS $(0.998)$ or OS $(p=0.444)$.

\section{Toxicity profile}

The toxicity profile shows that no G3 toxicity occurred related to eIORT. Two patients $(6.45 \%)$ exhibited acute G2 neuropathic pain. Late neuropathic pain was seen in 6 patients (12.9\%), with 3 being graded as G1 and 3 as G2 in severity, without any functional impairment and complete resolution after medical treatment. No woundrelated toxicity was found (Table 2).

\section{Discussion}

Although the improvement in operative and adjuvant treatment techniques during the past decades, sarcomas are still associated with an increased risk of mortality amongst all cancers [27, 6]. Under our hypothesis, for which IORT provides improved metastasis-free and overall survival, besides the already proven local control benefit, we sought to intensify local therapy by the addition of eIORT, as surgery-alone or perioperative EBRT-alone historical data have shown mixed data regarding these outcomes [28, 11, 12, 29].

Despite the fact that the vast majority of our patients (>80\%) presented with recurrent sarcoma, the local 


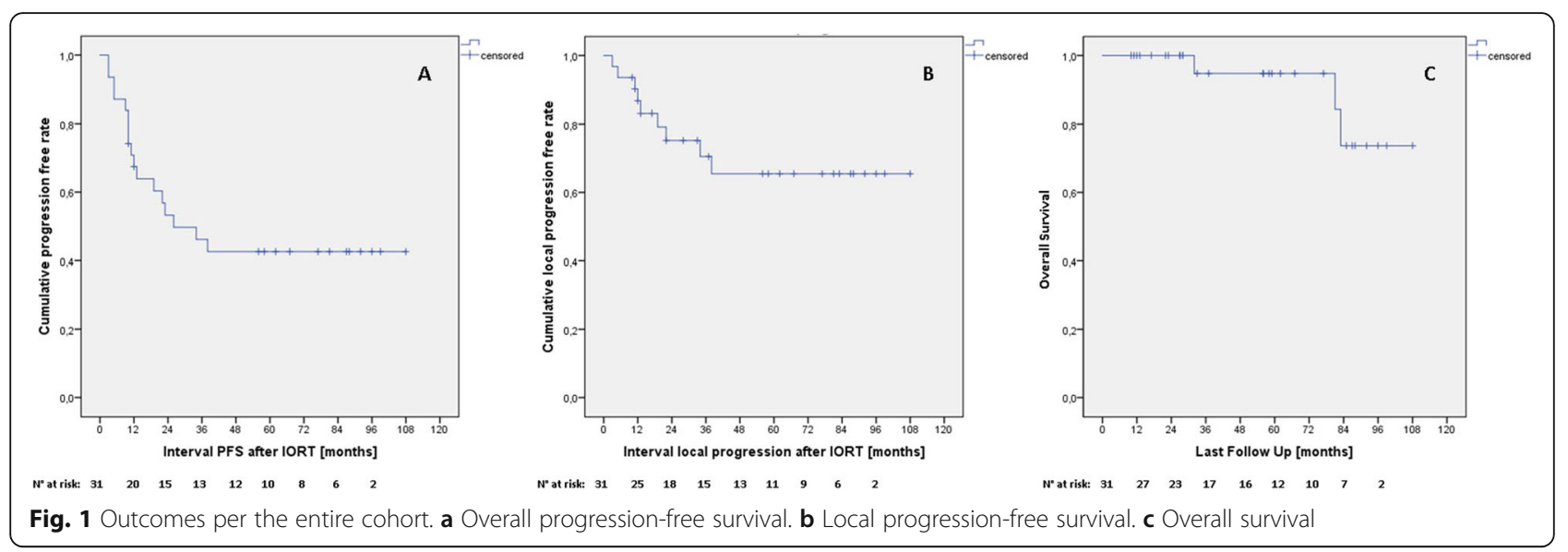

control rates appear specifically encouraging in comparison with previous data from other limb-sparing approaches [30, 7, 31]. Although there is a high variability of L-PFS, D-PFS and OS rates due to multiple factors (such as location, resection margins, grade, etc.), the 5-year OS rate seen in our collective (83.3-92\%) compares favorably with previous reports on IORT for recurrent sarcoma:

Call et al. reported on outcomes of 61 patients with upper-extremity sarcoma treated with surgery plus IORT (electrons or HDR), with the majority of patients being diagnosed with primary tumors (53 patients, 87\%). The 5 year local control for previously untreated and recurrent tumors was 94 and $67 \%$. Distant control and overall survival (OS) rates were 82 and 70\% for newly diagnosed and 74 and $63 \%$ for recurrent tumors. Interestingly, there was no significant difference regarding the resection status, R0 or R1, for all 3 endpoints evaluated, indicating efficacy of the approach. Four patients experienced severe adverse events that were judged to be related to IORT ( 2 wound complications, 1 severe neuropathy and 1 vascular necrosis of the humeral head) [32].

Haddock et al. reported the outcomes of 91 patients with primary $(n=74)$ or recurrent $(n=17)$ limb and girdle sarcomas, who underwent perioperative EBRT and electron-based IORT (IOERT). After a median follow-up of 2.5 years, the L-PFS was $92 \%$. Twenty-three patients developed distant progression, mostly pulmonary. The OS at 3 years was $76 \%$. In this analysis, a statistically significant difference was found between resection status and local control [33].

Recently Roeder et al. analyzed 183 patients with primary limb sarcoma (78\% primaries, 22\% recurrent) treated with IOERT at an average dose of $15 \mathrm{~Gy}$ [34]. After a median follow-up of 64 months, the L-PFS rates at 5 and 10 years were 86 and $84 \%$, whereas the resection status also influenced this in great fashion (5-year L-PFS rates were $92 \%$ vs $75 \%$ for R0 and $\mathrm{R}+$ ). Similarly, primary and recurrent tumors responded differently with 5 -year L-PFS rates of 90 and 74\% [34].

Calvo et al. described a potential benefit for high-risk features in patients who underwent electron-IORT with incomplete or close resection margins in comparison to historical reports on post-surgery EBRT-only patients. The L-PFS and OS rates after 5 years were 82 and $72 \%$ respectively, which could be compared to patients with more favorable features who showed L-PFS and OS rates of $72-96 \%$ and $71-87 \%$ respectively [35].

Another report from Roeder et al. addressed the outcomes of 27 patients treated in primary or recurrent scenarios for retroperitoneal sarcomas. Most of the patients

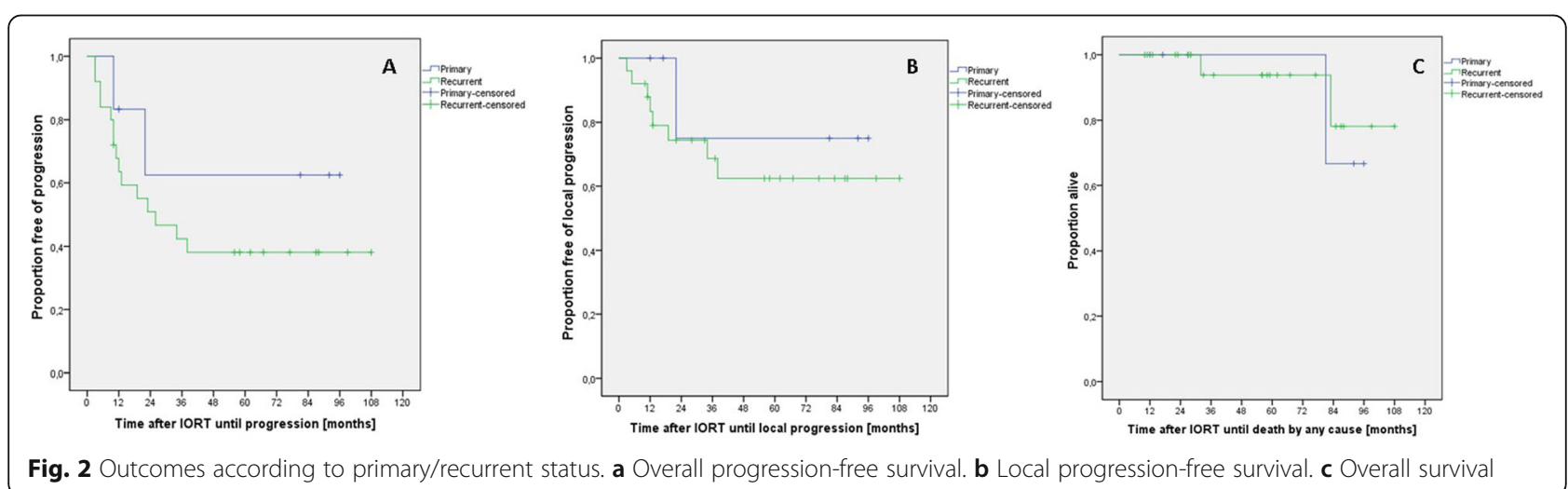


Table 2 Toxicity

\begin{tabular}{lll}
\hline Toxicity (CTC AE Grade) & N (events) & $\%$ \\
\hline Acute toxicity & 22 & 71.0 \\
Grade 0 & 2 & 6.5 \\
Grade 1 & 0 & 0 \\
Grade 2 & 0 & 0 \\
Grade 3 & 0 & 0 \\
Grade 4 & 7 & 22.6 \\
Not reported & & \\
Late toxicity & 15 & 48.4 \\
Grade 0 & 3 & 9.7 \\
Grade 1 & 3 & 9.7 \\
Grade 2 & 0 & 0 \\
Grade 3 & 0 & 0 \\
Grade 4 & 10 & 32.3 \\
Not reported & &
\end{tabular}

had neoadjuvant EBRT (median dose 50 Gy). The margins status was complete (R0) in $22 \%$ of the cohort and margin-positive (R1) in $74 \%$ of the patients. Out of this group $85 \%$ received IORT to a median dose of $12 \mathrm{~Gy}$. With a median follow-up of 33 months, the L-PFS was $72 \%$, O-PFS $63 \%$ and OS $74 \%$ at 5 years-estimated analysis [36].

All these results show good outcomes in terms of local control despite the increased rate of positive resection margins (R1-R2) and recurrent nature of the malignancies, which are similar to the ones registered in this study. This reinforces the importance of IORT in highrisk features scenario.

Similarly to the previously mentioned publications, the dose range for IORT should be fixed in the range of 10 to $20 \mathrm{~Gy}$, according to the recently published American Brachytherapy Society recommendations [37]. The selected doses for our cohort are supported by multiple factors, such as previous irradiation, organs-at-risk exposure and the relative biological effectiveness (RBE) of kilovoltage therapies. An adopted RBE factor of 1.3 has been standardized in our institution, based on published evidence regarding this topic [38]. Additional considerations must be taken into account depending on the selected applicator. In cases were a flat applicator was employed, the normalizations was done at $5 \mathrm{~mm}$ [21]. For the spherical applicators, a dose prescription is superficially determined; however, a dose distribution of approximately $30 \%$ is reached at $1 \mathrm{~cm}$ distance [38]. All this factors should be kept present when prescribing eIORT management.

As for OS only a few trials have addressed this evaluation. A recently published systematic review by Albertsmeier et al. has described a significant OS benefit in patients with retroperitoneal sarcomas who underwent prior EBRT to surgery, analyzing 554 patients with an OR of $0.37(p<0.00001)$. They describe as well that this benefit would be potentially greater in patients with positive resection margins. Despite these findings, there was no benefit demonstrated out of 2428 patients who had primary limb sarcoma diagnosis, although local control shows better outcomes [39, 40]. Our study shows really encouraging OS outcomes for a cohort conformed by mostly recurrent patients. These results might be supported by many factors, such as the improvement of healthcare for metastatic patients, localized radical radiotherapy and systemic treatments, yielding an overall improvement of survival rates [41]. An additional factor not to be disregarded is the idiosyncrasy of these tumors, as they develop in more extended time periods, compared to other malignancies.

For metastatic-scenario patients, current recommendations point to radical primary treatment and aggressive targeted treatment depending on the clinical status [42]. A new therapeutic window appears, as some papers have described a potential benefit of triggering the bystander and abscopal effect by high-dose delivery to primary or metastatic tumor areas. Intraoperative radiation therapy emerges as a good alternative due to its conformal nature and good tolerability with less expected secondary effects as SBRT deliver. Although more data is warranted, initial reports are encouraging due to their favorable outcomes in survival benefit [43-45].

Another, although less commonly used method of IORT is HDR brachytherapy with multi-catheter placement or flab applicators, which allow shaping the target area as the anatomy presents, at the same time prescribing precisely the extension of margins desired. Some of the longest follow-up date has been published based on HDR and electron-IORT experiences, which show solid data supporting this approach $[46,47]$. However, the logistics are challenging as surgical theaters must be adequately shielded due to radiation protection requirements [48].

Low-energy photons have reappeared in scene for the past few years, as different trials have shown their versatility for eIORT approach in many different scenarios as primary breast, brain, skin, metastatic, amongst others described [22, 23, 49]. Due to its nature, the portable linear accelerator can be used without major prerequisites into mostly any surgical theater (e.g. that is cleared for $\mathrm{C}$-arm fluoroscopy), as the $50-\mathrm{kV}$ nominal energy delivered plus local shielding is more than sufficient for accomplishing radioprotection regulations [26]. The availability of different applicators allows shaping to most of the surgical beds as needed. In our series, the most commonly used applicator was the spherical applicator, as it allowed covering the entire cavity in $360^{\circ}$ by approaching the surrounding tissues together. 
The sharp dose fall-off of low-energy photons is adequate for avoiding most risk structures and protecting the surrounding normal tissue [50] to keep the incidence of toxicity low [32].

The toxicity profile seen in our analysis was deemed acceptable, as no severe complications pre or postoperative were seen and only G2 toxicity was found during follow-up, considering that a large proportion $(n=$ 14) of this cohort debuted with intracavitary primaries, which is also reported in similar fashion by other groups. This might be explained by the limited tissue irradiated with IORT, as larger EBRT volumes could be avoided, which is of specific interest in the recurrent setting.

In our series, 25 patients were previously treated, whereas 10 of those remained without any evidence of local recurrence during follow-up, considering the recurrent nature of these tumors and accounting that over than $30 \%$ of this group had positive resection margins. No severe toxicity was developed during controls. It's worth mentioning that, amongst the limitations of this approach, the coverage of an entire surgical bed might not be possible in many cases, therefore a thorough follow-up assessment of the selected area to treat must be considered. However, selecting the high-risk area to treat in a large resection cavity should not raise greater concern, due to the large experience and generated evidence through the years with this very same technique application [51].

\section{Conclusion}

Taken together, with all limitations of a retrospective study and a heterogeneous cohort of patients, eIORT for limb and intracavitary STS seems to be of benefit regarding safety profile and L-PFS. Prospective evaluation is warranted to confirm these findings.

\section{Abbreviations}

STS: Soft-tissue sarcoma; IORT: Intraoperative radiotherapy; elORT: Electronic intraoperative radiotherapy; O-PFS: Overall progression-free survival; LPFS: Local progression-free survival; OS: Overall survival; HDR: High-dose rate brachytherapy; EBRT: External-beam radiotherapy; IOERT: Electron-based intraoperative radiotherapy

\section{Acknowledgements}

Not applicable.

\section{Authors' contributions}

GRS: Data collection, design, statistics and manuscript writing. VP: Data collection. FW: Design of study, supervision and revision of manuscript. YA: Analysis and review of statistical data. ES: Statistical data analysis and manuscript review. FAG: Manuscript writing and review, design and data analysis. The author(s) read and approved the final manuscript.

\section{Funding}

No funding was received for this research.

Availability of data and materials

Data not available.
Ethics approval and consent to participate

This study was approved by the local ethics committee, according to institutional policies. All patients gave informed consent prior to treatment.

\section{Consent for publication}

Not applicable due to absence of any personal or individual data in the present publication.

\section{Competing interests}

G.R.S: Grants and personal fees from Carl Zeiss Meditec, outside the submitted work.

V.P.: Nothing to disclose.

F.W.: Reports personal fees from Celgene $\mathrm{GmbH}$, personal fees from Roche Pharma AG, personal fees from Eli Lilly and Company, personal fees from Ipsen Pharma GmbH, grants and other from Carl Zeiss Meditec AG, grants and other from Elekta $A B$, outside the submitted work; In addition, Dr. Wenz has a patent Carl Zeiss Meditec AG licensed.

Y.A.: Reports personal fees from Carl-Zeiss Meditec, personal fees from Merck-Serono, non-financial support from Elekta, outside the submitted work.

E.S.: Grants from Ministry for Science and Arts, during the conduct of the study; other from Zeiss Meditec, outside the submitted work.

F.A.G.: reports other from Implacit $\mathrm{GmbH}$, non-financial support from Oncare $\mathrm{GmbH}$, grants and personal fees from NOXXON Pharma AG, grants and personal fees from CARL ZEISS MEDITEC AG, personal fees from Bristol-Myers Squibb, personal fees from Roche Pharma AG, personal fees from MSD Sharp and Dohme $\mathrm{GmbH}$, personal fees from AstraZeneca $\mathrm{GmbH}$, outside the submitted work; In addition, Dr. Giordano has a patent (US 62/435405) pending.

\section{Author details}

'Department of Radiation Oncology, University Medical Center Mannheim, Medical Faculty Mannheim, Heidelberg University, Theodor-Kutzer-Ufer 1-3, 68167 Mannheim, Germany. ${ }^{2}$ University Medical Center Freiburg, Medical Faculty Freiburg, Freiburg University, Freiburg, Germany. ${ }^{3}$ Department of Radiation Oncology, University Hospital Bonn, University of Bonn, Venusberg Campus 1, 53127 Bonn, Germany.

Received: 21 January 2020 Accepted: 3 May 2020

Published online: 14 May 2020

\section{References}

1. Saltus CW, Calingaert B, Candrilli S, et al. Epidemiology of adult soft-tissue sarcomas in Germany. Sarcoma. 2018;2018:5671926.

2. Mastrangelo G, Coindre JM, Ducimetiere F, et al. Incidence of soft tissue sarcoma and beyond: a population-based prospective study in 3 European regions. Cancer. 2012;118(21):5339-48.

3. Bray F, Ferlay J, Soerjomataram I, et al. Global cancer statistics 2018: GLOBOCAN estimates of incidence and mortality worldwide for 36 cancers in 185 countries. CA Cancer J Clin. 2018;68(6):394-424.

4. Siegel RL, Miller KD, Jemal A. Cancer statistics, 2018. CA Cancer J Clin. 2018; 68(1):7-30.

5. Potter JW, Jones KB, Barrott JJ. Sarcoma-the standard-bearer in cancer discovery. Crit Rev Oncol Hematol. 2018;126:1-5.

6. Nandra R, Hwang N, Matharu GS, et al. One-year mortality in patients with bone and soft tissue sarcomas as an indicator of delay in presentation. Ann R Coll Surg Engl. 2015;97(6):425-33.

7. Daigeler A, Zmarsly I, Hirsch T, et al. Long-term outcome after local recurrence of soft tissue sarcoma: a retrospective analysis of factors predictive of survival in 135 patients with locally recurrent soft tissue sarcoma. Br J Cancer. 2014;110(6):1456-64.

8. Trovik CS, Bauer HCF, Alvegård TA, et al. Surgical margins, local recurrence and metastasis in soft tissue sarcomas. Eur J Cancer. 2000;36(6):710-6.

9. Rosenberg SA, Tepper J, Glatstein E, et al. The treatment of soft-tissue sarcomas of the extremities: prospective randomized evaluations of (1) limb-sparing surgery plus radiation therapy compared with amputation and (2) the role of adjuvant chemotherapy. Ann Surg. 1982;196(3):305-15.

10. Casali PG, Abecassis N, Bauer $\mathrm{S}$, et al. Soft tissue and visceral sarcomas: ESMO-EURACAN clinical practice guidelines for diagnosis, treatment and follow-up. Ann Oncol. 2018;29:iv51-67. 
11. Pisters PW, Harrison LB, Leung DH, et al. Long-term results of a prospective randomized trial of adjuvant brachytherapy in soft tissue sarcoma. J Clin Oncol. 1996;14(3):859-68.

12. Yang JC, Chang AE, Baker AR, et al. Randomized prospective study of the benefit of adjuvant radiation therapy in the treatment of soft tissue sarcomas of the extremity. J Clin Oncol. 1998;16(1):197-203.

13. Shah C, Verma V, Takiar R, et al. Radiation therapy in the Management of Soft Tissue Sarcoma: a Clinician's guide to timing, techniques, and targets. Am J Clin Oncol. 2016;39(6):630-5.

14. Nussbaum DRC, Lane W, Cardona D, Kirsch D, Peterson B, et al. Preoperative or postoperative radiotherapy versus surgery alone for retroperitoneal sarcoma: a case-control, propensity score-matched analysis of a nationwide clinical oncology database. Lancet Oncol. 2016;17(7):966-75.

15. Muratori F, Frenos F, Bettini L, et al. Liposarcoma: Clinico-pathological analysis, prognostic factors and survival in a series of 307 patients treated at a single institution. J Orthop Sci. 2018;23(6):1038-44.

16. Roeder F, Krempien R. Intraoperative radiation therapy (IORT) in soft-tissue sarcoma. Radiat Oncol. 2017;12(1):20.

17. Abe M, Takahashi M. Intraoperative radiotherapy: the Japanese experience. Int J Radiat Oncol Biol Phys. 1981;7(7):863-8.

18. Kinsella TJ, Sindelar WF, Lack E, et al. Preliminary results of a randomized study of adjuvant radiation therapy in resectable adult retroperitoneal soft tissue sarcomas. J Clin Oncol. 1988;6(1):18-25.

19. Strohmaier S, Zwierzchowski G. Comparison of (60) co and (192) Ir sources in HDR brachytherapy. J Contemp Brachytherapy. 2011;3(4):199-208.

20. Manir KS, Basu A, Choudhury KB, et al. Interstitial brachytherapy in soft tissue sarcoma: a 5 years institutional experience with cobalt 60-based high-dose-rate brachytherapy system. J Contemp Brachytherapy. 2018;10(5):431-8.

21. Schneider F, Clausen S, Tholking J, et al. A novel approach for superficial intraoperative radiotherapy (IORT) using a $50 \mathrm{kV}$ X-ray source: a technical and case report. J Appl Clin Med Phys. 2014;15(1):4502.

22. Vaidya JS, Wenz F, Bulsara M, et al. Risk-adapted targeted intraoperative radiotherapy versus whole-breast radiotherapy for breast cancer: 5-year results for local control and overall survival from the TARGIT-A randomised trial. Lancet. 2014;383(9917):603-13.

23. Giordano FA, Brehmer $S$, Murle $B$, et al. Intraoperative radiotherapy in newly diagnosed Glioblastoma (INTRAGO): an open-label, Dose-Escalation Phase I/ II Trial. Neurosurgery. 2018.

24. Wenz F, Schneider F, Neumaier C, et al. Kypho-IORT--a novel approach of intraoperative radiotherapy during kyphoplasty for vertebral metastases. Radiat Oncol. 2010;5:11.

25. Schmidt R, Wenz F, Reis $T$, et al. Kyphoplasty and intra-operative radiotheray, combination of kyphoplasty and intra-operative radiation for spinal metastases: technical feasibility of a novel approach. Int Orthop. 2012;36(6): 1255-60.

26. Sethi A, Emami B, Small W Jr, et al. Intraoperative radiotherapy with INTRABEAM: technical and Dosimetric considerations. Front Oncol. 2018:8:74

27. Maretty-Nielsen K, Aggerholm-Pedersen N, Keller J, et al. Relative mortality in soft tissue sarcoma patients: a Danish population-based cohort study. BMC Cancer. 2014;14:682

28. Cahlon O, Brennan MF, Jia X, et al. A postoperative nomogram for local recurrence risk in extremity soft tissue sarcomas after limb-sparing surgery without adjuvant radiation. Ann Surg. 2012:255(2):343-7.

29. Kosela-Paterczyk H, Szacht M, Morysinski T, et al. Preoperative hypofractionated radiotherapy in the treatment of localized soft tissue sarcomas. Eur J Surg Oncol. 2014;40(12):1641-7.

30. Abatzoglou S, Turcotte RE, Adoubali A, et al. Local recurrence after initial multidisciplinary management of soft tissue sarcoma: is there a way out? Clin Orthop Relat Res. 2010;468(11):3012-8.

31. Kim HJ, Koom WS, Cho J, et al. Efficacy of postoperative radiotherapy using modern techniques in patients with retroperitoneal soft tissue sarcoma. Yonsei Med J. 2018;59(9):1049-56.

32. Call JA, Stafford SL, Petersen IA, et al. Use of intraoperative radiotherapy for upper-extremity soft-tissue sarcomas: analysis of disease outcomes and toxicity. Am J Clin Oncol. 2014;37(1):81-5.

33. Haddock MG, Petersen IA, Pritchard $D$, et al. IORT in the management of extremity and limb girdle soft tissue sarcomas. Front Radiat Ther Oncol. 1997:31:151-2

34. Roeder F, Lehner B, Schmitt T, et al. Excellent local control with IOERT and postoperative EBRT in high grade extremity sarcoma: results from a subgroup analysis of a prospective trial. BMC Cancer. 2014;14:350.
35. Calvo FA, Sole CV, Polo A, et al. Limb-sparing management with surgical resection, external-beam and intraoperative electron-beam radiation therapy boost for patients with primary soft tissue sarcoma of the extremity: a multicentric pooled analysis of long-term outcomes. Strahlenther Onkol. 2014;190(10):891-8.

36. Roeder F, Ulrich A, Habl G, et al. Clinical phase I/II trial to investigate preoperative dose-escalated intensity-modulated radiation therapy (IMRT) and intraoperative radiation therapy (IORT) in patients with retroperitoneal soft tissue sarcoma: interim analysis. BMC Cancer. 2014;14:617.

37. Tom MC, Joshi N, Vicini F, et al. The American brachytherapy society consensus statement on intraoperative radiation therapy. Brachytherapy. 2019;18(3):242-57.

38. Liu Q, Schneider F, Ma L, et al. Relative biologic effectiveness (RBE) of 50 kV $X$-rays measured in a phantom for intraoperative tumor-bed irradiation. Int J Radiat Oncol Biol Phys. 2013;85(4):1127-33.

39. Albertsmeier $M$, Rauch $A$, Roeder F, et al. External beam radiation therapy for Resectable soft tissue sarcoma: a systematic review and meta-analysis. Ann Surg Oncol. 2018;25(3):754-67.

40. Albertsmeier M, Roeder F, Angele MK. ASO Author Reflections: Radiation Therapy in Soft Tissue Sarcoma: Who Benefits and How? Ann Surg Oncol. 2018;25(Suppl 3):934-5.

41. Palma DA, Olson $\mathrm{R}$, Harrow $\mathrm{S}$, et al. Stereotactic ablative radiotherapy versus standard of care palliative treatment in patients with oligometastatic cancers (SABR-COMET): a randomised, phase 2, open-label trial. Lancet. 2019;393(10185):2051-8.

42. Trans-Atlantic Retroperitoneal Sarcoma Working G. Management of metastatic retroperitoneal sarcoma: a consensus approach from the transAtlantic retroperitoneal sarcoma working group (TARPSWG). Ann Oncol. 2018;29(4):857-71.

43. Marconi R, Strolin S, Bossi G, et al. A meta-analysis of the abscopal effect in preclinical models: is the biologically effective dose a relevant physical trigger? PLoS One. 2017;12(2):e0171559.

44. Brix $\mathrm{N}$, Tiefenthaller $\mathrm{A}$, Anders $\mathrm{H}$, et al. Abscopal, immunological effects of radiotherapy: narrowing the gap between clinical and preclinical experiences. Immunol Rev. 2017;280(1):249-79.

45. Palma DA, Olson RA, Harrow S, et al. Stereotactic ablative radiation therapy for the comprehensive treatment of oligometastatic tumors (SABR-COMET): results of a randomized trial. Int J Radiat Oncol Biol Phys. 2018;102(3):S3-4.

46. Folkert MR, Tong WY, LaQuaglia MP, et al. 20-year experience with intraoperative high-dose-rate brachytherapy for pediatric sarcoma: outcomes, toxicity, and practice recommendations. Int J Radiat Oncol Biol Phys. 2014;90(2):362-8

47. Roeder F, de Paoli A, Saleh-Ebrahimi L, et al. Intraoperative Electron radiation therapy combined with external beam radiation therapy after gross Total resection in extremity soft tissue sarcoma: a European pooled analysis. Ann Surg Oncol. 2018;25(13):3833-42.

48. Mailhot Vega $R$, Talcott $W$, Ishaq $O$, et al. A national survey of HDR source knowledge among practicing radiation oncologists and residents: establishing a willingness-to-pay threshold for cobalt-60 usage. Brachytherapy. 2017:16(4):910-5.

49. Goubert M, Parent L. Dosimetric characterization of INTRABEAM(R) miniature accelerator flat and surface applicators for dermatologic applications. Phys Med. 2015;31(3):224-32.

50. Hensley FW. Present state and issues in IORT physics. Radiat Oncol. 2017; 12(1):37.

51. Calvo F, Sole C, Herranz R, et al. Intraoperative radiotherapy with electrons: fundamentals, results, and innovation. Ecancermedicalscience. 2013;7:339.

\section{Publisher's Note}

Springer Nature remains neutral with regard to jurisdictional claims in published maps and institutional affiliations. 